\title{
Hepatitis C and Hemodialysis: A Review
}

\author{
Regina Célia Moreira1, Marcilio Figueiredo Lemos ${ }^{1,2}$, \\ Carlos Alberto Longui ${ }^{3}$ and Celso Granato ${ }^{4}$
}

\begin{abstract}
${ }^{1}$ Laboratory of Hepatitis, Virology Service, Adolfo Lutz Institute; ${ }^{2}$ Irmandade da Santa Casa de Misericórdia de São Paulo; ${ }^{3}$ Molecular Medicine Laboratory - Santa Casa de São Paulo - Faculty of Medical Sciences; ${ }^{4}$ Department of Infectious and Parasitic Infections of the Federal University of São Paulo, Medical School; São Paulo, SP, Brazil
\end{abstract}

\begin{abstract}
Hepatitis $\mathrm{C}$ is a serious public health problem throughout the world; chronic renal patients are highly exposed to this infection. This could be due to a failure to identify carriers of this disease or because of a lack of truly effective biosafety measures implemented in the dialysis units. Molecular biology techniques have allowed for the understanding of this virus in detail, including its replication mechanisms. Epidemiological studies have been made throughout the world, with the goal of determining the dissemination dynamics of this agent, in addition to examining the predominance of the different genotypes, and the possible mutants that are involved. Many questions must still be answered concerning infection by Hepatitis $\mathrm{C}$ virus (HCV); this is especially important for immunosuppressed patients.

Key Words: Hepatitis C (HCV), hemodialysis.
\end{abstract}

With technological advances in studies concerning the Hepatitis $\mathrm{C}$ virus (HCV), the elaboration and the implementation of diagnostic tests, such as triage in blood banks that began in 1990, has allowed professionals to understand the dimension of the Hepatitis C problem. It is known today that approximately 200 million people worldwide are infected by HCV [1]. The main transmission route of $\mathrm{HCV}$ is parenteral [1-3]; however, approximately $10 \%$ of the cases are sporadic, without well-defined transmission routes [4,5].

The populations most affected by $\mathrm{HCV}$ are patients that undergo multiple blood transfusions, individuals who are intravenous and inhalant drug

Received on 17 March 2005; revised 31 July 2005.

Address for correspondence: Dr. Regina Célia Moreira. Rua Praia do Castelo n ${ }^{\circ} 99$ apto 64, Vila Mascote. Zip code: 04362020, São Paulo, SP, Brazil. Phone: 55 - 11 - 3068-2911 - 55652144. Fax: 55 - 11 -3088-3753.E-mail: rmoreira@ial.sp.gov.br /mflemos@ial.sp.gov.br

The Brazilian Journal of Infectious Diseases 2005;9(3):269-275 (C) 2005 by The Brazilian Journal of Infectious Diseases and Contexto Publishing. All rights reserved. users, hemophiliacs, and hemodialysis patients [1,5]. The high prevalence of $\mathrm{HCV}$ infections in patients that undergo hemodialysis has been described worldwide [6-10].

Mosconi [11], in an analysis of 185 serum samples of chronic renal patients from Bologna, Italy, utilizing ELISA and second-generation Immunoblotting (IB) tests, observed HCV infection in $38 \%$ of them. The number of transfusions and the duration of dialysis affected the prevalence rates in this population.

Hayashi [12], in a serum-epidemiological study, undertaken in two cities in Japan, analyzed the serum of hemodialysis patients and compared them to the general population. They observed a prevalence of $3.3 \%$ for the general population of Fukuoka and of $51.6 \%$ in the hemodialysis patients, while in Okinawa, the rates were $0.4 \%$ and $9.1 \%$ for the general population and hemodialysis patients, respectively.

Pujol [7], in a study of four dialysis units in Caracas, Venezuela, observed alarming prevalence and incidence rates of $\mathrm{HCV}$. The observed prevalence rate was $71 \%$ and the incidence rate, in the period between 1994 and 1995 , was $38 \%$. 
Tokars [9] carried out a national vigilance study in dialysis centers in the United States in 1995. There were 2,647 centers, totaling 244,954 patients, and the prevalence of $\mathrm{HCV}$ was $10.4 \%$.

The cause for the elevated prevalence of $\mathrm{HCV}$ infection in hemodialysis patients may be due to the excessive number of transfusions that these patients are frequently submitted to [13], and since the prevalence increases with the duration of dialysis treatment, there is an indication that the environment itself functions as a vehicle in the dissemination of the virus among the patients in dialysis centers [14-19].

Medin [20] did a retrospective study with 236 patients in dialysis centers in Stockholm, and he determined the period of serological conversion for $\mathrm{HCV}$ in 23 patients, emphasizing that $80 \%$ of them had undergone blood transfusion. He raised the hypothesis that the number of transfusions is not always trustworthy, due to the fact that patients often receive transfusions in other services, not notifying this fact in the local unit.

Some studies [20,21] on patients positive and negative for anti-HCV did not find a correlation between dissemination of the virus in the dialysis units and sharing of the machines or rooms between the patients. In other reports, there was a lower incidence of infection in the units that use separate machines and rooms for patients that test positive for anti-HCV [15,22-26]. Dos Santos [26] observed a lower incidence in the centers that separate patients who are positive for anti-HCV and in those that use separate rooms for the reutilization of the dialyzers.

Hepatitis $\mathrm{C}$ virus does not penetrate the membrane pores of the dialyzer; the size of the virus is 10 times greater than the dialysis membrane pores [19]. However, the virus could pass if an accidental rupture of the membrane occurs $[6,27,28]$.

Cendoroglo-Neto [17], in a study made on serum samples of 185 patients that had undergone hemodialysis and on 124 patients in treatment with Continuous Ambulatory Peritoneal Dialysis (CAPD), observed a significant difference in the prevalence of infections by the Hepatitis B and C viruses between the two groups. The duration of hemodialysis treatment, the number of transfusions and the environment were the main factors determining the risk for Hepatitis B and $\mathrm{C}$ transmission, which explains the high infection prevalence in hemodialysis patients compared to those who undergo CAPD.

Morales [29], in a study concerning the prevalence and incidence of infection by $\mathrm{HCV}$ in hemodialysis, observed that $70 \%$ of the patients positive for antiHCV had undergone blood transfusion. Sayiner [8] carried out a study in Turkey that compared patients in hemodialysis with those on CAPD treatment. They observed a $6.8 \%$ anti-HCV prevalence in CAPD patients, while the hemodialysis patients had a prevalence of $45.7 \%$. The duration of dialysis, the number of transfusions, as well as the number of units of blood received, were the principal factors contributing to the elevated prevalence among hemodialysis patients.

Sandhu [30], in a study done in Canada in 1999, observed that the factors most frequently related to the condition of the HCV infection carrier are the duration of dialysis treatment, ALT alterations for more than six months, and history of transplants prior to 1990. Blood transfusion, by itself, was not an important factor for the dissemination of the infection.

Basic biosafety measures are recommended for all dialysis centers, with the aim of protecting the patients and employees. These basic measures were recommended by the CDC (1988), with the goal of minimizing the dissemination of blood-transmitted agents in the dialysis units, including Hepatitis $\mathrm{B}$ and $\mathrm{C}$ viruses. De Lamballerie [31], in a study concerning nosocomial transmission of $\mathrm{HCV}$ in patients submitted to hemodialysis, observed some important factors in the dissemination of this agent in several centers. The main factors were immunodeficiency in chronic renal patients, invasive procedures, which are frequent in these patients, and blood transfusion.

Several authors cite as a risk for $\mathrm{HCV}$ dissemination between patients, hemodialysis sessions in the same room, in the same time-period or in adjacent rooms, with patients who are carriers of $\mathrm{HCV}$ infection [15,22-26].

In a study carried out in dialysis centers in Belgium, Jadoul [32] reported, based on the analysis of 15 units 
that had been followed up for 54 months, a reduction in the incidence of hepatitis $C$ virus infection, with the incidence tending to zero. The only changes were the universal biosafety measures recommended by the CDC.

Hemodialysis treatment in Brazil began in 1950, with the implementation of the dialysis service and the first kidney transplant. In 1960, Nephrology was included as a distinct discipline in clinical medicine, followed by the creation of the Brazilian Society of Nephrology [33].

In 1996, the Brazilian Health Ministry published a directive, establishing rules for the functioning of the substitutive renal therapy services, taking into account the necessity of defining a standard of quality and safety, and aiming at the reduction of morbidity and mortality rates. This directive determined that serology for Hepatitis $\mathrm{B}$ and $\mathrm{C}$ be done on a monthly basis, along with biochemical evaluations, such as ALT determination [34]. This directive was published for a second time in 2000 [35].

Even with the implementation of the standards and biosafety rules, the prevalence of infection by $\mathrm{HCV}$ in patients submitted to hemodialysis treatment continues to be high. In order to reduce this quotient, we need to understand the dissemination dynamics of this virus in the dialysis units. Lowering the incidence rates of infection is a goal for professionals involved in the study of viral Hepatitis throughout the world.

Moraes [6] performed a case-control study on 813 patients undergoing dialysis and on 772 apparently healthy adult individuals considered as controls, in the state of Santa Catarina, Brazil. The observed prevalence of $\mathrm{HCV}$ was $33.4 \%$ for the patients and $0.8 \%$ for the controls. Besides these populations, data was obtained on the employees of the dialysis units, with an observed prevalence of $2.7 \%$ for this third group. The most frequent genotypes were: $1 \mathrm{~b}, 3 \mathrm{a}$, and $1 \mathrm{a}$.

Prevalence data for patients submitted to hemodialysis in Brazil varied from $23.8 \%$ in the Northeastern region, to $45.5 \%$ in the Northern region, and $46.7 \%$ in the Midwest region. The mean prevalence in the population in the Southeast region was $35.3 \%$ [36,37].
Santana [38], in a study involving 395 patients submitted to hemodialysis, in different units in the city of Salvador, Bahia, Brazil, collected information regarding the number of blood transfusions in $75.4 \%$ of the patients; He concluded that the positivity of anti$\mathrm{HCV}$ increases with the number of transfusions. Among these 298 patients, 48 had not received blood and 6 $(12.5 \%)$ of these tested anti-HCV positive. Of the 250 that had already received at least one transfusion, 64 (25.6\%) were anti-HCV positive. The prevalence found in this study (23.8\%) was roughly 13 times greater than that estimated for blood donors $(1.7 \%)$ in this municipal district.

Moreira [39], in a prospective study, observed a $14.6 \%$ prevalence of $\mathrm{HCV}$ infection and an incidence of 3.1/1000 affected individuals/month, in an analysis of chronic renal patients from two dialysis centers in the metropolitan region of São Paulo, Brazil. Simmonds [40], using ELISA and $2^{\text {nd }}$ generation IB tests, performed antibody detection on 217 patients undergoing hemodialysis. They observed a $97.5 \%$ concordance between the two methods.

Al Meshari [41] demonstrated that immunoenzymatic tests can fail in the detection of hemodialysis patients who are carriers of HCV infection; an explanation for this fact would be the weak immune response of chronic renal patients to a great variety of antigenic stimuli or to the uremic condition itself. According to Tokars [9], the immunoenzymatic test fails to detect $10 \%$ of the infected patients.

Even with the use of $3^{\text {rd }}$ generation tests, false negative and false positive results are still observed. The immunoenzymatic tests may fail to detect individuals with active $\mathrm{HCV}$ infection. During the acute phase of the disease, anti-HCV antibodies are not detected by any test developed thus far. Among the chronic renal patients, with known immune disorders, the seronegativity period may be even more ample. The incorporation of the viral envelope proteins could be an alternative for the development of more sensitive, new immunoenzymatic tests. However, due to the existence of hyper-variable regions in these proteins, the intrinsic difficulties in developing these tests may never be surpassed [42]. 
Moraes [6], in a study made on hemodialysis patients in the state of Santa Catarina, Brazil, using ELISA and IB antibody detection techniques, both $3^{\text {rd }}$ generation, found a $98.2 \%$ concordance between the two methods. The IB test has high specificity, providing separately-reacting antibodies for each viral antigen, therefore being important for the confirmation of positive serology obtained in the ELISA test. The IB test is not routine in hemodialysis units, , probably because of its high cost, and its difficult execution and interpretation. Its incorporation as a complementary test to the ELISA may reduce the errors observed in the screening of the patients, thus avoiding the false positive and false negative results.

Molecular biology techniques are the most efficient tools for the identification of HCV strains, useful both for diagnosis and for viral characterization studies. The Polymerase Chain Reaction (PCR) techniquewhen used for HCV infection, allows the identification of the acute phase of the infection. This is very important, considering that anti-HCV antibodies are not detected during this phase. Furthermore, the detection of antibodies does not differentiate between past and present infections. Consequently, both PCR and serology cannot distinguish acute from chronic cases [41]. Nevertheless, the separation of HCV-infected patients from $\mathrm{HCV}$ carriers, as is done with $\mathrm{HBV}$ infected patients and $\mathrm{HBV}$ carriers, is still controversial. Umlauft [43], in a study focusing on Hepatitis C viremia standards in patients that have undergone hemodialysis, in seven dialysis centers in Austria and one in Northern Italy, observed fluctuation in the degree of viremia in one-third of the patients with positive PCR, with periods of up to four weeks of undetectable HCVRNA. Pujol [7] also observed that ALT levels do not help in the screening of $\mathrm{HCV}$ carriers in dialysis centers. Schneeberger [44], in an HCV infection vigilance study in dialysis centers in Holland, observed that of the 2,576 samples with negative serology, six had HCV RNA. According to these authors, the PCR, along with antibody detection, should be "gold standards" for the diagnosis of HCV in dialysis centers. They emphasize that among patients submitted to hemodialysis, various causes can provoke alterations in the serum levels of aminotransferases, which makes these tests relatively unspecific [45].

Carneiro [37] demonstrated, in a study of 428 patients conducted in the central region of Brazil, that $10.3 \%$ of the patients that tested negative for $\mathrm{HCV}$ were $\mathrm{HCV}$ RNA positive. He concluded that PCR should be included in the screening of hemodialysis patients.

Moreira [39] observed that the monthly determination of ALT does not aid in the early detection of HCV infection. The values that were observed were within the normal upper limit for ALT in both carrier patients and non-carrier patients. Izopet [23], in a prospective study of hemodialysis patients, did not identify any patient with negative serology using ELISA, yet had positive results using PCR.

Piazza [46] in an HCV vigilance study, starting in 1992 , observed that $72 \%$ of the patients with positive serology also tested positive with PCR. Five years later, continuing with the same program, they observed similar results (75\%). Sterling [47] did not observe a correlation between ALT alteration, viral load, or hepatic histology, in patients with terminal renal disease and HCV infection.

The false negative results may place $\mathrm{HCV}$-infected patients in contact with chronic renal patients negative for this agent, while false positive results may result in the exposure of HCV-negative patients. We should bear in mind that patients who undergo hemodialysis, often not only share the same room, but also the same machines, and though the virus does not penetrate the filters, it could accidentally pass through the membranes and contaminate these machines, placing at risk patients who undergo therapy with the same unit.

Careful and adequate laboratory practices, such as the incorporation of more than one diagnostic technique, such as the IB and PCR tests, and serology in more than one serum sample could help avoid false positive and negative results. Since PCR detects RNA and indicates the presence of circulating antigen in the affected individual, it could be the technique of choice as a complementary test to serology, allowing the detection of viremia in a period prior to serologic conversion, as has been demonstrated by several studies [39]. 
Molecular studies on HCV have contributed to various epidemiological studies, and in an attempt to study HCV dissemination in dialysis centers, several researchers have used genotyping techniques for the characterization of circulating viral strains. Allander et al. [14] were the first to determine the similarity of the nucleotide sequence among hemodialysis patients, to characterize HCV dissemination among them. They observed that 5 out of 14 patients with positive serology for HCV had been contaminated with the same viral strain, and that two other patients had been infected with two strains from different genotypes. These patients did not receive blood transfusions and did not share the same dialysis machine, however they shared the same room. They used sequencing of the E2/NS1 region to characterize the nosocomial transmission of HCV in a dialysis unit. De Lamballerie [31] characterized nosocomial transmission by the identification of the circulating HCV genotypes in a dialysis center, through characterization of the viral envelope region.

Norder et al. [48], analyzed the NS5B genomic segment to determine the HCV transmission chain in hemodialysis patients. They demonstrated the transmission chain by characterizing the strains and the source of contamination, by analyzing serum from patients who presented serologic conversion during the study and through serum analysis of nurses who worked in the respective centers.

Mizuno [49], also using molecular characterization techniques, detected the dissemination of $\mathrm{HCV}$ in two dialysis centers in Japan. By sequencing the hypervariable 1 region, they made a phylogenetic and serological study of the viral strains, determining transmission routes between patients.

In a study carried out by Fabrizi [50], a predominance of the 2 a genotype was observed, followed by the $1 \mathrm{~b}$ genotype and genotypes 3 and 4 , which were observed in $3.0 \%$ of the population. This data differed from that observed in the general population and in other epidemiological studies done in Italy.

Zein [51] emphasized that the differences between the genotypes may affect the diagnostic tests, especially in regions where there is a high prevalence of genotypes different from 1a, which is used in tests throughout the world, causing high rates of false negative results.

Busek [52] in a study done in the city of Belo Horizonte, Minas Gerais, Brazil, reported a prevalence of $20.3 \%$ for anti-HCV; this was 4.6 times greater than the prevalence of Hepatitis B virus (4.4\%). In this same study, the HCV genotypes were determined for 83 patients positive for $\mathrm{HCV}-\mathrm{RNA}$; $66 \%$ belonged to genotype $1,24 \%$ to genotype 2 and $7.2 \%$ to genotype 3 . Genotype 4 was only found in one patient. They concluded that the use of multiple dialysis units, the total duration of the treatment, and the high number of blood transfusions were important factors that determined $\mathrm{HCV}$ contamination.

Moreira [39] examined the dissemination of HCV in dialysis centers in the city of São Paulo, SP, Brazil, looking for predominance of a single genotype in patients who underwent the procedure in the same dialysis unit. They detected genotype $4 \mathrm{HCV}$, which is rare in this country, in two patients who underwent treatment in the same period/shift and in machines that were near each other.

The 5'NCR region is the most practical region for genotyping; but it is the most conserved, so it is not the best region to establish transmission chains within dialysis units, even though it is possible to identify all the amplified samples.

The PCR method can be used for the verification of false positive and negative results, for the early diagnosis of $\mathrm{HCV}$ infection, as well as for determining the circulation of viral strains belonging to the same genotype, confirming the presence of the Hepatitis C virus in hemodialysis environments.

There is a need for more studies and for the implementation of preventive and control measures of this infection in chronic renal patients.. Epidemiological studies and the continuous follow-up of Hepatitis C virus infection in dialysis units are of great importance for public health throughout the world. These should include implementation of new methodologies and improvement of the infrastructure of the centers; these measures could help improve the quality of life of dialysis patients. 


\section{Acknowledgements}

We are grateful to the Support Center for Scientific Publications of Santa Casa de São Paulo - Faculty of Medical Sciences for editorial assistance.

\section{References}

1. Quer J., Esteban J.I. Hepatitis C virus: Epidemiology. In: Zuckerman A.J., Thomas H.C. eds. Viral Hepatitis. London: Churchill Livingstone, 1998.

2. Alter M.J. Epidemiology of hepatitis C. Hepatology 1997;26:62-5.

3. Center for Disease Control. Recommendations for prevention and control of hepatitis $\mathrm{C}$ virus (HCV) infection and HCV-related chronic disease. MMWR Recomm Rep 1998; 47(RR-19):1-39.

4. Houghton M. Hepatitis C virus. In: Fields B.N., Knipe D.M., Howley P.M. eds. Virology. Philadelphia: Lippincott-Raven Publishers, 1996.

5. Alter M.J. Prevention of spread of hepatitis C. Hepatology 2002;36:S93-8.

6. Moraes C.R., Carrilho F.J., Bassit L.C., et al. Hepatitis C virus infection in hemodialysis patients from southern Brazil. Epidemiological data and genotypes. Hepatology 2000;32:546 A.

7. Pujol F.H., Ponce J.G., Lema M.G., et al. High incidence of hepatitis $\mathrm{C}$ virus infection in hemodialysis patients in units with high prevalence. J Clin Microbiol 1996; 34 : $1633-6$.

8. Sayiner A.A., Zeytinoglu A., Ozkahya M., et al. HCV infection in haemodialysis and CAPD patients. Nephrol Dial Transplant 1999; 14:256-7.

9. Tokars J.I., Miller E.R., Alter M.J., Arduino M.J. National surveillance of dialysis associated diseases in the United States, 1995. ASAIO J 1998;44:98-107.

10. Vanderborght B.O., Rouzere C., Ginuino C.F., et al. High prevalence of hepatitis $\mathrm{C}$ infection among Brazilian hemodialysis patients in Rio de Janeiro: a one-year follow-up study. Rev Inst Med Trop Sao Paulo 1995;37:75-9.

11. Mosconi G., Campieri C., Miniero R. et al. Epidemiology of hepatitis $\mathrm{C}$ in a population of hemodialysis patients. Nephron 1992;61:298-9.

12. Hayashi J., Yoshimura E., Nabeshima A., et al. Seroepidemiology of hepatitis $\mathrm{C}$ virus infection in hemodialysis patients and the general population in Fukuoka and Okinawa, Japan. J Gastroenterol 1994;29:276-81.
13. Mallick N.P., Gokal R. Haemodialysis. Lancet 1999;353:737-42.

14. Allander T., Medin C., Jacobson S.H., et al. Hepatitis C transmission in a hemodialysis unit: molecular evidence for spread of virus among patients not sharing equipment. J Med Virol 1994;43:415-9.

15. Chiaramonte S., Tagger A., Ribero M.L., et al. Prevention of viral hepatitis in dialysis units: isolation and technical management of dialysis. Nephron 1992;61:287-9.

16. Covic A., Iancu L., Apetrei C., et al. Hepatitis virus infection in haemodialysis patients from Moldavia. Nephrol Dial Transplant 1999; 14:40-5.

17. Cendoroglo Neto M., Draibe S.A., Silva A.E., et al. Incidence of and risk factors for hepatitis B virus and hepatitis $\mathrm{C}$ virus infection among haemodialysis and CAPD patients: evidence for environmental transmission. Nephrol Dial Transplant 1995;10:240-6.

18. Cendoroglo Neto M., Manzano S.I., Canziani M.E., et al. Environmental transmission of hepatitis B and hepatitis $\mathrm{C}$ viruses within the hemodialysis unit. Artif Organs 1995; 19:251-5.

19. Sampietro M., Badalamenti S., Graziani G. Nosocomial hepatitis $C$ in dialysis units. Nephon 1996;74:251-60.

20. Medin C., Allander T., Roll M., et al. Seroconversion to hepatitis $\mathrm{C}$ virus in dialysis patients: a retrospective and prospective study. Nephron 1993;65:40-5.

21. Jadoul M., Cornu C., Van Ypersele De Strihou. Incidence and risk factors for hepatitis $\mathrm{C}$ seroconversion in hemodialysis: a prospective study. The UCL Collaborative Group. Kidney Int 1993;44:1322-6.

22. Blumberg A., Zehnder C., Burckhardt J.J. Prevention of hepatitis $\mathrm{C}$ infection in haemodialysis units. A prospective study. Nephrol Dial Transplant 1995;10:230-3.

23. Izopet J., Pasquier C., Sandres K., et al. Molecular evidence for nosocomial transmission of hepatitis $\mathrm{C}$ virus in a French hemodialysis unit. J Med Virol 1999;58:139-44.

24. Pascual J., Teruel J.L., Liano F., Ortuno J. Home hemodialysis protects against hepatitis $\mathrm{C}$ virus transmission. Nephron 1993;64:314.

25. Pru C.E., Cuervo C., Ardila M., Teran M. Hepatitis C transmission through dialysis machines. ASAIO J 1994;40:M889-91.

26. Dos Santos J.P., Loureiro A., Cendoroglo Neto M., Pereira B.J. Impact of dialysis room and reuse strategies on the incidence of hepatitis $\mathrm{C}$ virus infection in haemodialysis units. Nephrol Dial Transplant 1996;11:2017-22.

27. Hubmann R., Zazgornik J., Gabriel C., et al. Hepatitis C virus-does it penetrate the haemodialysis membrane? PCR analysis of haemodialysis ultrafiltrate and whole blood. Nephrol Dial Transplant 1995;10:541-2.

28. Valtuille R., Fernandez J.L., Berridi J., et al. Evidence of hepatitis $\mathrm{C}$ virus passage across dialysis membrane. Nephron 1998;80:194-6. 
29. Morales M.F., Lossi J.S., Alderete T.N., Noli D. Prevalence and seroconversion to $\mathrm{HCV}$ in hemodialyzed patients, and epidemiological factors. Transpl Proc 1996;28:3402-5.

30. Sandhu J., Preiksaitis J.K., Campbell P.M., et al. Hepatitis $\mathrm{C}$ prevalence and risk factors in the northern Alberta dialysis population. Am J Epidemiol 1999; 150:58-66.

31. De Lamballerie X., Olmer M., Bouchouareb D., et al. Nosocomial transmission of hepatitis $C$ virus in haemodialysis patients. J Med Virol 1996;49:296-302.

32. Jadoul M., Cornu C., Van Ypersele De Strihou. Universal precautions prevent hepatitis $\mathrm{C}$ virus transmission: a 54 month follow-up of the Belgian Multicenter Study. The Universitaires Cliniques St-Luc (UCL) Collaborative Group. Kidney Int 1998;53:1022-5.

33. Noronha I.L., Schor N., Coelho S.N., et al. Nephrology, dialysis and transplantation in Brazil. Nephrol Dial Transplant 1997;12:2234-43.

34. Ministério da Saúde. Portaria ${ }^{\circ} 2042$, de 11 de outubro de 1996. Diário Oficial da União 199, Seção I, 20792-8, 14 de outubro de 1996.

35. Ministério da Saúde. Portaria $n^{\circ} 82$, de 3 de janeiro de 2000. Diário Oficial da União 27 - E, Seção I, 08 de fevereiro de $\mathbf{2 0 0 0 .}$

36. Fonseca J.C.F., Lobato C., Farias F.E., et al. Epidemiologia da infecção pelo vírus da hepatite $\mathrm{C}$ no Brasil. Gastrenterologia Endoscopia Digestiva 1999;18:3-9.

37. Carneiro M.A., Martins R.M., Teles S.A., et al. Hepatitis $\mathrm{C}$ prevalence and risk factors in hemodialysis patients in Central Brazil: a survey by polymerase chain reaction and serological methods. Mem Inst Oswaldo Cruz 2001;96:765-9.

38. Santana G.O., Cotrim H.P., Mota E., et al. [Antibodies to hepatitis $\mathrm{C}$ virus in patients undergoing hemodialysis in Salvador, BA, Brazil]. Arq Gastroenterol 2001;38:24-31.

39. Moreira R., Pinho J.R., Fares J., et al. Prospective study of hepatitis $\mathrm{C}$ virus infection in hemodialysis patients by monthly analysis of HCV RNA and antibodies. Can J Microbiol 2003;49:503-7.

40. Simmonds P., Alberti A., Alter H.J., et al. A proposed system for the nomenclature of hepatitis $\mathrm{C}$ viral genotypes. Hepatology 1994;19:1321-4.

41. Al Meshari K., Al Ahdal M., Alfurayh O., et al. New insights into hepatitis $\mathrm{C}$ virus infection of hemodialysis patients: the implications. Am J Kidney Dis 1995;25:572-8.

42. Gretch D.R. Diagnostic tests for hepatitis C. Hepatology 1997;26:S43-7.

43. Umlauft F., Gruenewald K., Weiss G., et al. Patterns of hepatitis $\mathrm{C}$ viremia in patients receiving hemodialysis. Am J Gastroentrol 1997;92:73-8.

44. Schneeberger P.M., Keur I., van der V., et al. Hepatitis C virus infections in dialysis centers in The Netherlands: a national survey by serological and molecular methods. J Clin Microbiol 1998;36:1711-5.
45. Pratt D.S., Kaplan M.M. Evaluation of abnormal liverenzyme results in asymptomatic patients. $\mathrm{N}$ England $\mathrm{J}$ Med 2000;342:1266-71.

46. Piazza V., Cristina G., Montagna G., et al. Long-term persistence of hepatitis $\mathrm{C}$ viremia in hemodialysis patients. Clin Nephrol 1999;51:129-30.

47. Sterling R.K., Sanyal A.J., Luketic V.A., et al. Chronic hepatitis $\mathrm{C}$ infection in patients with end stage renal disease: characterization of liver histology and viral load in patients awaiting renal transplantation. Am J Gastroenterol 1999;94:3576-82.

48. Norder H., Bergstrom A., Uhnoo I., et al. Confirmation of nosocomial transmission of hepatitis $\mathrm{C}$ virus by phylogenetic analysis of the NS5-B region. J Clin Microbiol 1998;36:3066-9.

49. Mizuno M., Higuchi T., Kanmatsuse K., Esumi M. Genetic and serological evidence for multiple instances of unrecognized transmission of hepatitis $\mathrm{C}$ virus in hemodialysis units. J Clin Microbiol 1998;36: 2926-31.

50. Fabrizi F., Lunghi G., Guarnori I., et al. Hepatitis C virus genotypes in chronic dialysis patients. Nephrol Dial Transplant 1996; 11:679-83.

51. Zein N.N. Clinical significance of hepatitis $C$ virus genotypes. Clin Microbiol Rev 2000;13:223-35.

52. Busek S.U., Baba E.H., Tavares Filho H.A., et al. Hepatitis $\mathrm{C}$ and hepatitis $\mathrm{B}$ virus infection in different hemodialysis units in Belo Horizonte, Minas Gerais, Brazil. Mem Inst Oswaldo Cruz 2002;97:775-8. 